\title{
Do Western Companies Appropriately Adapt Their Indonesian Promotional Websites to an Indonesian Audience? A Study Applying Content Analysis of Cultural Cues Reveals Some Answers
}

\author{
Philip Michael Ross Smith ${ }^{1}$, Adrian Wee Tiong Weng ${ }^{1}$, Suhor Anuar ${ }^{1} \&$ Thanapat Kijbumrung ${ }^{1}$ \\ ${ }^{1}$ School of Business and Management, RMIT University, Vietnam \\ Correspondence: Philip Michael Ross Smith, School of Business and Management, RMIT University, 702 \\ Nguyen Van Linh, HCMC, Vietnam. Tel: 84-8-3776-1300. E-mail: phil.smith@rmit.edu.vn
}

Received: October 14, 2018

doi:10.5539/ass.v14n12p274
Accepted: October 21, 2018 Online Published: November 29, 2018

URL: https://doi.org/10.5539/ass.v14n12p274

\begin{abstract}
This study explores the depiction of local culture in the Indonesian websites of English and American companies operating in Indonesia. The objective is to evaluate if the websites have been adapted to the local culture of Indonesia. Content analysis was employed in the analysis utilising an instrument applied in many similar types of research on website content analysis. Results of the study suggest that more effort is needed by the foreign companies to adapt their websites to this local cultural environment, particularly with regards to the cultural dimensions of high context, collectivism and power distance.
\end{abstract}

Keywords: websites, culture, Hofstede, Indonesia

\section{Introduction}

The use of the internet has grown exponentially since its introduction in the early 1990's, and more recently emerging markets have seen a pronounced expansion in internet use. Indonesia, in particular, has seen the number of internet users rise from 89 million in 2015 to 104 million in 2017 (Statista, 2018) and prompted in part by the rapid adoption of the smartphone. According to Statista (2018), the number of internet users in Indonesia is expected to climb to 134 million users in 2022 reaching more than half of the population in one of the world's largest online markets.

Indonesia was chosen not only because of its large number of online users but also because of its increasing importance in the region. Indonesia has the largest economy in Southeast Asia totalling 930 billion USD GDP per annum and a large and growing population of 260 million (World Bank 2018). The country is also a member of the G-20, and classified as a newly industrialised economy, very much in the same category as India and China (World Bank, 2018).

In the era of the World Wide Web, the most popular method for businesses to access online users is through websites. Businesses use websites to disclose organisational details, disseminate pertinent information, build strong relationships and interact with stakeholders (Cyr \& Trevor-Smith, 2004; Chiou et al., 2010; Shin et al., 2015). However, communicating with online users via websites can be difficult because of the influence of national culture on such communications.

Different cultures have diverse preferences regarding website design and content (Singh et al., 2003; Cyr et al., 2004; Cyr, 2008). Thus a culturally relevant website would encourage users to browse through its contents while a culturally inappropriate website could repel users. The purpose of this research is to measure the depiction of local Indonesian culture in the Indonesian websites of English and American companies operating in Indonesia. It aims to ascertain if the Indonesian websites of foreign companies have considered cultural preferences in communication style and other expectations of local culture. Moreover, if not culturally appropriate, how and what can the companies do to adapt their websites to reach out more effectively to the Indonesian consumer.

This study utilised the method developed by Singh et al. (2003) to analyse and measure the depiction of culture on the English and American companies' Indonesian websites. It will then test a set of hypotheses that highlight the predicted cultural differences between Western and Indonesia culture found in these Indonesian Websites thus indicating the extent of any adaptation made. The assessment framework is based primarily on two culturally prominent academic Edward T. Hall (1976) and Geert Hofstede (2001) and combined in a widely 
applied instrument developed by Nitish Singh. Over the years and multiple studies, the framework has been empirically validated and determined to be reliable (Singh et al., 2003; Singh \& Matsuo, 2004; Singh et al., 2006; Chun et al., 2015).

This study is particularly important as it fulfills the need for cultural research in the Indonesian context and thus meet a gap in Indonesian website understanding relating to cultural adaptation of websites. The explosive growth in the use of the internet and the dramatic rise of e-commerce in the region have only added urgency to this type of study in the country.

\section{Literature Review}

International businesses are faced with an important issue when attempting to reach out to online users; namely, should businesses internationalise or localise their primary online presence, their websites? Here, localization refers to the process of adapting websites to the needs and demands of local consumers, including local language, symbols, numerals and other local cultural preferences (Singh et al., 2004). Standardization, on the other hand, refers to the idea that the websites of a company should have a similar look and feel to promote consistency and convenience, and hence much less effort for the web-designer and company (Cyr \& Trevor Smith, 2004).

Much research has been conducted in seeking to evaluate and understand the effects of cultural communication cues within web design. Some of these studies have focused on web design elements such as layout, structure, navigational links and visuals (Cyr, 2013). Other studies have concentrated on the underlying cultural values and beliefs that influence the designs (Singh et al., 2003; Singh et al., 2004).

Regardless of the focus, almost all the research found that cultures vary in their preferences for website design and content. Badre (2000) finds that online users tend to favour websites that exhibit familiar cultural markers such as colours, pictures, symbols, rituals, heroes or values that denote their unique culture. Similarly, Luna et al. (2002) note that websites that adapt to local culture are more lucid and accessible, facilitating local users' approval. Baack and Singh (2007), Hsieh (2014) adds that websites that incorporate local cultural elements would also be more usable. That is, the websites would be better able to communicate with users..

Trust in the company and message of the website has also been shown to be a product of culturally compatible elements within the site. Bartikowski and Singh (2014), point out that culturally adapted websites generate positive user attitudes and trust. Further, Cyr (2013), Pengnate \& Sarathy (2017) and Thorpe (2016) linked culturally congruent websites to user trust, user satisfaction and loyalty. All in online users are more likely to visit and remain on websites that are culturally appropriate and culturally sensitive (Barber \& Badre, 1998).

With these benefits in mind, many international businesses have localised their websites (Singh et al., 2004). Some of them furnishing multiple websites, by building customised websites for the different markets or regions in which they work. They may also develop websites for each market and each product line offered. However, Cyr and Trevor Smith (2004) note that international companies often do not do enough in adapting their websites to local culture. They point out that many international businesses seldom go beyond translating the language or delivering primary graphical interfaces with local designs while distinctive cultural elements such as values, beliefs, customs, and symbols are ignored.

This paper aims to examine the depiction of local culture on the Indonesian websites of English and American companies in Indonesia. The focus of this study is thus to determine if the websites have adapted to local culture. This paper also plans to provide greater insight and recommendations on developing culturally adapted websites for the Indonesian market.

First, some background on the meaning of concepts applied regarding culture and the dimensions applied in the study. There are many definitions of culture. The most common definitions include references to variations in attitudes, values, beliefs and behavioural norms. Hofstede (2001) for example, describes culture as mental programming or how a group of people think, feel and behave. Culture has long been the subject of extensive studies. Moreover, some frameworks or models have been developed to explain differences in culture. While Hall and Hall (1990) explore differences in communication styles, Kluckhohn and Strodtbeck (1961), Hofstede (2001) and Trompenaars (1996) examines differences in values and beliefs.

Nonetheless, the most popular and most utilized model is that of Hofstede's value dimensions. This model is based on Hofstede's study on 176,000 respondents, working in IBM offices all around the world. The model asserts that cultures differ with regards to their inclination toward collectivism, power distance, uncertainty avoidance and masculinity (Hofstede, 2001).

The components, called cultural dimensions utilized are defined below along with the predicted relative intensity between Western and Indonesian culture and hypothesis development: 
Collectivism dimension relates to social orientation. Collectivist cultures emphasise group while individualist cultures prioritise the individual. The collectivist believes that it is best to maintain close ties with group members while the individualist believes in more independence. The collectivists believe that it is best to close ranks and work together with group members to survive and compete in the world they live in (Hofstede, 2001; Trompenaars, 2012).

Singh et al. (2005) note that websites that value the collective group will promote the family, community work, group discussions and programmes that encourage loyalty. In contrast, websites that value the individual will endorse individual achievement, self-reliance, and self- recognition, with an emphasis on the uniqueness of the product sold. Indonesian culture is inherently much more collectivist than Western culture and this research should reflect the differences in the website cultural cues. Hypothesis 1 embodies this notion:

H1 The Indonesian websites of US and English companies should display higher collectivism than their local Websites in Western countries.

Individualism dimension relates to the importance placed on the individual (Hofstede 1980). Individualistic cultures focus on individual interest and individual goals whereas collectivistic cultures focus on group interest and group goals (Triandis et al., 1995). Western cultures are inherently much more individualistic than Indonesian culture and this research should reflect the differences in the website cultural cues as per Hypothesis 2.

H2 The Indonesian websites of US and English companies should display lower individualism than their local Websites in Western countries.

Uncertainty avoidance dimension relates to ambiguity or uncertainties (Hofstede, 1980). While high uncertainty avoidance cultures deem uncertainties as risks to avoid, low uncertainty avoidance cultures embrace uncertainties as challenges to overcome. Cultures differ in their tolerance for uncertainty and ambiguity. High uncertainty avoidance cultures view uncertainties as threats. Whilst low uncertainty avoidance cultures deem uncertainties as barriers (Hofstede, 2001).

Reinecke and Bernstein (2011) showed that users from high uncertainty avoidance cultures would prefer more formal and organised navigational links so that they would not get disoriented. In addition to navigational links, Singh et al. (2005) note that websites that integrate uncertainty avoidance would display comprehensive user support, contact information, company details and accurate use of local language (Singh et al., 2005). And on this dimension Western cultures score higher than most Asian cultures including Indonesia, reflecting their more risk-averse nature. The relationship is embodied in Hypothesis 3

H3 The Indonesian websites of US and English companies should display higher uncertainty avoidance than their local Websites in Western countries.

Power distance dimension refers to the distribution of social power (Hofstede, 1980). While low power distance cultures support equality and fairness, high power distance cultures accept and respect the hierarchical ladder. On this dimension, Western cultures score low while Indonesia is high. Cultures differ in their beliefs on power distribution. High power distance culture tolerates if not respects differential power. Low power distance culture, on the other hand often insists on equality and egalitarian practices. High power distance culture believes that observing formal rules and hierarchy will keep peace and harmony which is most important (Hofstede, 2001).

Singh et al. (2005) note that websites that embrace high power distance will emphasise organisational hierarchy, formal titles and many images of high ranking and influential people in the organisation. Websites that espouse low power distance, on the other hand, will highlight fair play and level playing ground. Hypothesis 4 captures the predicted relationship.

H4 The Indonesian websites of US and English companies should display higher power distance than their local Websites in Western countries.

Masculinity refers to masculine values (Hofstede, 1980). Masculine cultures emphasise ambition, achievement, and advancement, whereas Feminine cultures prioritize quality of life, relationships and security (Triandis et al. 1988). Indonesian culture is more feminine than the masculinised Western culture, and the relative intensity of dimensions found in the websites of each culture should reflect this. Cultures vary on their views on gender and social roles. Masculine cultures highlight competition, achievement, and clear gender roles. On the contrary, feminine cultures stress close relations, harmony and ambiguous gender roles (Hofstede, 2001).

Tsikriktsis (2002) proffers in his study that masculine cultures tend to have higher expectations for website quality, specifically regarding interactivity and design. Singh et al. (2005) maintain that websites incorporating 
the masculinity cultural elements would focus on aspects of product effectiveness such as product quality and product durability, with an emphasis on authenticity and veracity.

H5 The Indonesian websites of US and English companies should display lower masculinity than their local Websites in Western countries.

A further set of cultural dimensions applied in this study are those of Edward T. Hall whose work on cultural context gave rise to a set of cultural elements. These divide neatly into the classification of High Context and Low Context, with Western countries (and companies) displaying Low Context compared to the High Context values of Indonesia.

High Context Western cultures tend to be open, direct and explicit in their communication style. Conversely, Low Context cultures tend to be reserved, indirect and sensitive to the listener (Gudykunst et al. 1996). Hall and Hall (1990) further refer to users from High Context cultures rely more on trust with significant others and thus expect less detailed information. Hall and Hall (1990) also note that the same users have a strong preference for visuals and graphics. Singh et al. (2005) indicated that websites that integrate High Context would employ lots of bold colours and visual images, and use flowery language to show politeness and humility. These concepts are embodied in by the following two Hypotheses, $\mathrm{H} 6$ and $\mathrm{H} 7$.

H6 The Indonesian websites of US and English companies in should display lower levels of low context than their local Websites in Western countries.

H7 Indonesian websites of US and English companies should display higher levels of high context than their local Websites in Western countries.

These are summarised in the next section.

\section{Hypotheses}

The primary objective of this study is to examine if and how much of local culture has been incorporated into the Indonesian websites of English and American companies operating in Indonesia. To measure cultural depiction a widely adopted method of coding developed by Singh et al. (2003), Singh et al. (2005) is employed. Singh's coding sheet will be used to calculate the cultural scores of the Indonesian and domestic websites of English and American companies. The scores obtained will subsequently be compared with published Hofstede's value dimension scores on Indonesia, England and the United States.

This paper proposes that there will be some adaptation; that there will be some differences in scores between the domestic and Indonesian websites of English and American companies. More specifically, compared to their domestic websites, the Indonesian websites of English and American companies will display higher levels of high context, collectivism, power distance and uncertainty avoidance; and lower levels of low context, individualism and masculinity. This study will investigate this proposition by reviewing seven hypotheses that correspond to the five value or cultural dimensions that make up the Singh et al. (2003) framework as detailed above. In summary, H1 \& H2 address Collectivism and Individualism, H3 Uncertainty Avoidance dimension, H4 assess Power Distance, H5 refers to Masculinity-Femininity, while H6 and H7 address High and Low Context.

\section{Method}

Content analysis has been used to study everything from print media to advertising and marketing content. More recently it has been used to study websites, blogs, Facebook entries and other online content. Neuman (2007) notes that content analysis is a useful technique for analyzing any text-based content. Singh et al. (2005), Singh and Matsuo (2004), in turn, notes that content analysis has become a very well-established tool for objectively examining communication content including websites.

This study uses the content analysis method to evaluate the cultural content of Indonesian and domestic websites of English and American companies. Singh et al. (2003) provided a comprehensive framework for studying cultural content on the web utilising content analysis. The framework requires the use of a coding sheet that incorporates seven cultural dimensions and 35 coding categories.

The Indonesian and domestic websites of English and American companies served as samples for this study. The companies come from Forbes list of global companies (2017). However, only companies that have translated their Indonesian websites into the local language, Bahasa Indonesia were chosen. The research team reviewed a total of 82 websites, of these, the team only analysed 40 websites written in the local Bahasa Indonesian language. These websites met the local language requirement of the study. As mentioned, the unit of analysis is the websites and all the pages in the websites were analysed for cultural content using the coding sheet developed by Singh et al. (2003) and Singh et al. (2005). 
All measures on the coding sheet adopt a five-point Likert Scale, and hence the results could be made available to statistical calculations as a continuous variable. This view is supported by Bentler and Chow $(1987$, p. 88$)$ who argue that normally distributed categorical variables on a Likert-type scale, "continuous methods can be used with little worry when a variable has four or more categories". This view matches that of Garson (2005; 2012) when he states that the five-point Likert scale furnishes an adequate resolution to provide scale-data in SPSS. Furthermore in an article by Pell (2005) in referencing Carifion and Perla (2008) maintains that Likert items are not ordinal in character, but rather, are interval in nature and, thus, may be analysed parametrically with all the associated benefits and power of these higher levels of analyses.

In applying the Survey Instrument reproduced in Appendix 1, an analysis was carried out by two coders who rated each cultural dimension on the aforementioned Likert Scale.

\section{Results}

The websites were examined using the content analysis methods previously applied by Singh et al. (2005). A MANOVA statistical test conducted on SPSS (George, 2016) produced a set of results demonstrating the difference in mean values for each of the 24 variables aligned with a cultural measure. The results for each variable are given in Table 1.

Results of the examination of websites applying the content analysis methods described demonstrated significant differences for selected variables within each category of the cultural variable. The following sections discuss these differences.

Table 1. Descriptive Statistics and ANOVA for Cultural Categories for Indonesia and Anglo Websites

\begin{tabular}{|c|c|c|c|c|c|c|c|}
\hline Categories & $\begin{array}{l}\text { ANGLO } \\
\text { Web sites } \\
(n=38) \\
\text { MEAN }\end{array}$ & & $\begin{array}{l}\text { INDONESIA } \\
\text { Web sites } \\
(\mathbf{n}=\mathbf{3 8})\end{array}$ & & $\begin{array}{l}\text { F value } \\
(\mathrm{df}=1)\end{array}$ & $\mathbf{p}$ & Sig \\
\hline & Mean & SD & Mean & SD & & & \\
\hline \multicolumn{8}{|l|}{ Collectivism } \\
\hline Community & 4.82 & 0.51 & 4.03 & 0.91 & 21.54 & 0.000 & $* *$ \\
\hline Clubs & 4.29 & 0.52 & 3.45 & 1.31 & 13.62 & 0.000 & $* *$ \\
\hline Family theme & 3.18 & 0.80 & 3.42 & 0.98 & 1.34 & 0.050 & ns \\
\hline Loyalty & 2.92 & 1.34 & 2.74 & 1.31 & 0.37 & 0.547 & ns \\
\hline Newsletter & 2.97 & 0.72 & 2.92 & 1.24 & 0.05 & 0.821 & ns \\
\hline \multicolumn{8}{|l|}{ Individualis m } \\
\hline Independence & 4.68 & 0.47 & 3.95 & 0.57 & 37.97 & 0.000 & ** \\
\hline Product Uniqueness & 4.55 & 0.65 & 3.87 & 0.78 & 17.44 & 0.000 & $* *$ \\
\hline Personalized & 2.42 & 0.50 & 2.13 & 0.62 & 4.99 & 0.028 & ns \\
\hline \multicolumn{8}{|l|}{$\begin{array}{l}\text { Uncertainty } \\
\text { Avoidance }\end{array}$} \\
\hline Customer Service & 4.26 & 0.92 & 3.97 & 1.20 & 1.40 & 0.241 & ns \\
\hline Guided Navigation & 4.97 & 0.16 & 4.61 & 0.55 & 15.83 & 0.000 & $* *$ \\
\hline Local Stores & 3.76 & 1.05 & 3.97 & 1.20 & 0.66 & 0.418 & ns \\
\hline Local Terminology & 5.00 & 0.00 & 3.90 & 0.45 & 226.63 & 0.000 & $* *$ \\
\hline Tradition Theme & 3.32 & 0.47 & 2.76 & 0.75 & 14.77 & 0.000 & $* *$ \\
\hline \multicolumn{8}{|l|}{ Power Distance } \\
\hline Company Hierarchy & 3.92 & 0.49 & 2.13 & 1.32 & 61.59 & 0.000 & $* *$ \\
\hline Images of CEO's & 4.68 & 0.74 & 2.37 & 1.44 & 77.69 & 0.000 & $* *$ \\
\hline Formal Titles & 3.84 & 0.55 & 2.21 & 1.40 & 44.90 & 0.000 & $* *$ \\
\hline Vision Statement & 4.82 & 0.69 & 2.71 & 1.37 & 71.20 & 0.000 & $* *$ \\
\hline \multicolumn{8}{|l|}{ Masculinity } \\
\hline Product effectiveness & 4.24 & 0.85 & 4.13 & 1.02 & 0.24 & 0.626 & ns \\
\hline Realism & 4.18 & 0.51 & 3.95 & 0.52 & 4.02 & 0.049 & ns \\
\hline \multicolumn{8}{|l|}{ High Context } \\
\hline Aesthetics & 1.13 & 0.66 & 1.03 & 0.51 & 0.57 & 0.570 & ns \\
\hline Polite \& Indirect & 3.76 & 0.43 & 3.26 & 0.45 & 24.69 & 0.000 & ** \\
\hline Soft-sell approach & 4.24 & 0.43 & 3.71 & 0.65 & 17.17 & 0.000 & $* *$ \\
\hline \multicolumn{8}{|l|}{ Low Context } \\
\hline Hard-sell approach & 3.05 & 1.18 & 2.95 & 0.93 & 0.19 & 0.668 & ns \\
\hline Rank and Prestige & 4.76 & 0.71 & 3.29 & 0.73 & 78.93 & 0.000 & $* *$ \\
\hline Use of Superlatives & 1.08 & 0.27 & 1.11 & 0.39 & 0.12 & 0.734 & ns \\
\hline
\end{tabular}

\section{Summary of Results}

Each category of cultural dimension outlined in Table 1 reveals some individual variables, and many offer significant differences. When these are condensed to the cultural dimensions, they jointly represent through the application of an independent samples t-test in Table 2. The statistics given are applied to address our 
hypotheses.

Table 2. Independent Samples T-Test: Comparison of Indonesian to Anglo websites

\begin{tabular}{|l|r|r|r|r|r|r|r|r|}
\multicolumn{1}{|c|}{ Dimension } & $\begin{array}{c}\text { Indonesian } \\
\text { Website } \\
\text { Mean } \\
\text { Values }\end{array}$ & $\begin{array}{c}\text { SD } \\
\text { Indonesia }\end{array}$ & $\begin{array}{c}\text { Anglo } \\
\text { Website } \\
\text { Mean } \\
\text { Values }\end{array}$ & $\begin{array}{c}\text { SD } \\
\text { Anglo }\end{array}$ & T & df & p $<$ & $\begin{array}{c}\text { ETA } \\
\text { Sqrd }\end{array}$ \\
\hline Collectivism & 16.6 & 4.1 & 18.2 & 2.5 & 2.1 & 61.5 & 0.04 & $12 \%$ \\
\hline Individualism & 9.9 & 1.7 & 11.7 & 1.3 & 5.0 & 74.0 & 0.00 & $56 \%$ \\
\hline Uncertainty & 19.2 & 2.8 & 21.3 & 1.7 & 4.0 & 60.2 & 0.00 & $29 \%$ \\
\hline Avoidance & 9.4 & 4.5 & 17.3 & 2.3 & 9.5 & 55.1 & 0.00 & $78 \%$ \\
\hline Power & 8.1 & 1.2 & 8.4 & 1.1 & 1.3 & 73.3 & 0.20 & $10 \%$ \\
\hline Distance & 7.3 & 1.2 & 8.9 & 1.3 & 5.5 & 74.0 & 0.00 & $68 \%$ \\
\hline Masculinity & 11.0 & 1.1 & 12.1 & 0.9 & 4.7 & 74.0 & 0.00 & $51 \%$ \\
\hline Low Context & & & & & & & \\
\hline High Context & & & & & &
\end{tabular}

\section{Collectivism}

Notably, in Table 2, the results revealed a significant difference between the cultures of the English, American (Anglophone) and Indonesian when considered jointly on the variables of Community Relations; Clubs $\&$ Chatrooms; Family; Loyalty; Independence and Product Uniqueness. Wilk's $=.590, \mathrm{~F}(5,70)=.73, \mathrm{p}=.000$, partial $\boldsymbol{\eta}^{\mathbf{2}}=41$. Thus, overall a significant difference between the category of websites.

Table 1 lists the components comprising the Collectivism dimension indicating that when a separate ANOVA is conducted for each dependent variable, with each ANOVA evaluated at an alpha level of .01 (Bonferroni Adjusted). There was significant difference between Anglo and Indonesian culture on Community Relations, F $(1,74)=21.54, p=.000$, partial $\eta^{2}=.23$, with Anglo culture $(M=.82)$ scoring higher in the Indonesian website $(M=4.03)$, a result in the direction hypothesised. A significant difference was also found on the variable of Clubs \&Chatrooms, $\mathrm{F}(1,74)=13.62, \mathrm{p}=.000$, partial $\eta^{2}=.16$, with Anglo culture $(\mathrm{M}=4.29)$ scoring higher than Indonesian culture $(\mathrm{M}=3.45)$. This result too was as hypothesized and indicating that the foreign company has worked to adapt its website to the local culture.

There was not a significant difference between Anglo and Indonesian culture on the variables: Family, F $(1,74)$ $=3.97, p=.050$, partial $\eta^{2}=.05$; Loyalty, F $(1,74)=.367, p=.547$, partial $\boldsymbol{\eta}^{2}=.005$; Newsletter, F $(1,74)$ $=.051, \mathrm{p}=.821$, partial $\eta^{2}=.001$.

\section{Individualism}

Notably, in Table 2, the results revealed a significant difference between the cultures. The study found a significant difference between the cultures of Anglophone and Indonesian when considered jointly on the variables of Independence and Product Uniqueness. Wilk's $=.641, F(3,72)=13.43, p=.015$, partial $\eta^{\frac{2}{2}}=.36$.

Referring again to Table 1 under the Individualism Dimension. A separate ANOVA was conducted for each dependent variable, with each ANOVA evaluated at an alpha level of .017 (Bonferroni Adjusted). There was significant difference between Anglo and Indonesian culture on Independence, F $(1,74)=10.32, p=.000$, partial $\eta^{2}=.34$, with Anglo culture $(M=4.68)$ scoring higher than Indonesian culture $(M=3.95)$. A significant difference was also found on the variable of Product_Uniqueness $F(1,74)=8.90, p=.000$, partial $\eta^{2}=.19$, with Anglo culture $(M=4.55)$ scoring higher than Indonesian culture $(M=3.87)$. There was not a significant difference between Anglo and Indonesian culture on the variable Personalized F $(1,74)=1.59, p=.028$, partial $\eta^{2}=.06$. All statistically significant differences aligned with the hypothesized direction that the foreign companies have adapted their local Indonesian websites to the low individualism environment Indonesia.

\section{Uncertainty Avoidance}

Table 2 also reveals a significant difference between the cultures of Anglophone and Indonesian when considered jointly on the variables of Customer Service; Guided Navigation; Local Stores; Local Terminology; Tradition Theme. Wilk's $=.590, \mathrm{~F}(5,70)=7.73, \mathrm{p}=.000$, partial $\boldsymbol{\eta}^{2}=.41$.

Referring to Table 1 under the Uncertainty Avoidance dimension. In analysing the individual components contributing to the Uncertainty Avoidance dimension the researchers conducted a separate ANOVA for each dependent variable, with each ANOVA evaluated at an alpha level of .01 (Bonferroni Adjusted). There was significant difference between Anglo and Indonesian culture on Guided Navigation, F $(1,74)=15.83, p=.000$, partial $\eta^{2}=.176$, with Anglo culture $(M=4.97)$ scoring higher than Indonesian culture $(M=4.61)$. A significant difference was also found on the variable of Local Terminology, $F(1,74)=226.63, p=.000$, partial 
$\eta^{2}=.75$, with Anglo culture $(M=5.00)$ scoring higher than Indonesian culture $(M=3.90)$. A significant difference was also found on the variable of Tradition Theme, $F(1,74)=14.77, p=.000$, partial $\boldsymbol{\eta}^{2}=.166$, with Anglo culture $(M=3.32)$ scoring higher than Indonesian culture $(M=2.76)$.

Referring again to Table 1 under the Uncertainty Avoidance dimension. There was not a significant difference between Anglo and Indonesian culture on the variables: Customer Service, F $(1,74)=1.397, p=.241$, partial $\eta^{2}=.019$; Local Stores, $F(1,74)=.664, p=.418$, partial $\eta^{2}=.009$. However, all statistically significant differences among the variables aligned with the hypothesized direction confirming the cultural differences described by Hofstede's (1980) dimensions.

\section{Power Distance}

Referring again to Table 2 list of results. There was a significant difference between the cultures of Anglophone and Indonesian when considered jointly on the variables of Company Hierarchy; Images of CEO's; Formal Titles; and, Vision Statement. Wilk's $=.355, \mathrm{~F}(4,71)=7.73, \mathrm{p}=.000$, partial $\boldsymbol{\eta}^{2}=.65$.

Table 1 under the Power Distance dimension. A separate ANOVA was conducted for each dependent variable, with each ANOVA evaluated at an alpha level of .013 (Bonferroni Adjusted). There was significant difference between Anglo and Indonesian culture on Company Hierarchy, F $(1,74)=61.59, p=.000$, partial $\boldsymbol{\eta}^{2}=.454$, with Anglo culture $(M=3.921)$ scoring higher than Indonesian culture $(M=2.132)$. A significant difference was also found on the variable of Images of CEO's, $F(1,74)=77.692, p=.000$, partial $\eta^{2}=.907$, with Anglo culture $(M=4.684)$ scoring higher than Indonesian culture $(M=2.368)$. A further significant difference was also found on the variable of Formal Titles, $F(1,74)=44.895, p=.000$, partial $\boldsymbol{\eta}^{2}=.378$, with Anglo culture $(\mathrm{M}=$ 3.842) scoring higher than Indonesian culture $(\mathrm{M}=2.211)$. There was a significant difference in the variable of Vision Statement, $F(1,74)=71.197, \mathrm{p}=.000$, partial $\mathbf{\eta}^{\mathbf{2}}=.490$, with Anglo culture $(\mathrm{M}=4.816)$ scoring higher than Indonesian culture $(\mathrm{M}=2.711)$.

Of note is that all the differences measured are in the opposite direction to those hypothesized, and all variable relationships were significant.

\section{Masculinity}

The results listed in Table 2 and Table 1 indicate that no significant difference was evident between Anglo and Indonesian culture on the variables: Product Effectiveness, $F(1,74)=.239, p=.626$, partial $\eta^{2}=.003$; Realism Theme, $\mathrm{F}(1,74)=4.023, \mathrm{p}=.049$, partial $\boldsymbol{\eta}^{\mathbf{2}}=.052$. Thus, no conclusions can be drawn on this dimension.

\section{High Context}

The High Context component variables in Table 2 indicate there was a significant difference between the cultures of Anglophone and Indonesian when considered jointly on the variables of Aesthetics; Polite \& Indirect; Soft Sell Approach. Wilk's $=.696, \mathrm{~F}(3,72)=10.488, \mathrm{p}=.000$, partial $\eta^{2}=.304$.

A separate ANOVA was conducted for each dependent variable, results displayed in Table 1 with each ANOVA evaluated at an alpha level of .0167 (Bonferroni Adjusted). A significant difference was also found on the variable of Polite \& Indirect, $F(1,74)=24.689, p=.000$, partial $\eta^{2}=.250$, with Anglo culture $(M=3.763)$ scoring higher than Indonesian culture $(\mathrm{M}=3.263)$. A significant difference was also found on the variable of Soft Sell Approach, F $(1,74)=17.169, p=.000$, partial $\eta^{2}=.188$, with Anglo culture $(M=4.237)$ scoring higher than Indonesian culture $(\mathrm{M}=3.711)$. The results displaying a higher score for High Context in Anglo websites was in the opposite direction to those hypothesized.

There was not a significant difference between Anglo and Indonesian culture on the variable: Aesthetics, F $(1,74)$ $=.570, \mathrm{p}=.453$, partial $\eta^{2}=.008$;

\section{Low Context}

The Low Context component variables in Table 2 indicate there was a significant difference between the cultures of Anglophone and Indonesian when considered jointly on the variable of Hard Sell Approach; Co Rank \& Prestige; Superlatives. Wilk's $=.474, \mathrm{~F}(3,72)=26.626, \mathrm{p}=.000$, partial $\eta^{2}=.526$.

A separate ANOVA was conducted for each dependent variable, results displayed in Table 1, with each ANOVA evaluated at an alpha level of .0167 (Bonferroni Adjusted). A significant difference was also found on the variable of Co. Rank \& Prestige, $F(1,74)=78.933, p=.000$, partial $\eta^{2}=.516$, with Anglo culture $(\mathrm{M}=4.763)$ scoring higher than Indonesian culture $(\mathrm{M}=3.289)$. The result agrees with the hypothesized result and shows the adaptation of the website to the Indonesian culture. 
There was not a significant difference between Anglo and Indonesian culture on the variables: Hard Sell Approach, F $(1,74)=.186, p=.668$, partial $\eta^{2}=.003$; Superlatives, $F(1,74)=.117, p=.734$, partial $\eta^{2}$ $=.002$.

\section{Hypotheses Addressed}

The hypotheses are:

H1 The Indonesian websites of US and English companies should display higher collectivism than their local Websites in Western countries.

- The results for Hypothesis H1 are the reverse of those required of a culturally adapted website. The overall Collectivist values of the English and US domestic websites is slightly higher than that of the Indonesian websites, indicating an inability to communicate this cultural value. The subcomponents of Community Relations and Clubs \& Chatrooms of the website failed in sufficiently communicating Collectivist values.

H2 The Indonesian websites of US and English companies should display lower individualism than their local Websites in Western countries.

- The results for Hypothesis H2 show a lower level of Individualism in comparison with the English and US domestic websites and demonstrates successful adaptation to the lower individualistic culture of Indonesia. Surprisingly, the two components of the same cultural continuum, Individualism and Collectivism, show opposing results.

H3 The Indonesian websites of US and English companies should display higher uncertainty avoidance than their local Websites in Western countries.

- This research study does not confirm Hypothesis 3 because the Indonesian website of the foreign companies display a lower level of uncertainty avoidance and do not appear to have adapted to the local Indonesian environment sufficiently

H4 The Indonesian websites of US and English companies should display higher power distance than their local Websites in Western countries.

- Hypothesis 4 results are the opposite of those expected of a culturally adapted website. Table 2 indicates a failure of the foreign companies to adapt their Indonesian website to the high Power Distance culture of Indonesia.

H5 The Indonesian websites of US and English companies should display lower masculinity than their local Websites in Western countries.

- The results listed in Table 2 affirm Hypothesis 5 in which Indonesian websites exhibit a slightly lower Masculinity Index. However, the result was not significant.

H6 The Indonesian websites of US and English companies should display lower levels of Low Context than their local Websites in Western countries.

- Regarding the Low Context cultural dimension, the results indicate a much lower context in the foreign companies' local Indonesian websites. Therefore, they have appropriately adapted their website to the Indonesian cultural environment.

H7 The Indonesian websites of US and English companies should display a higher level of High Context than their local Websites in Western countries.

- The results of this measure are significant $(\mathrm{p}<.001)$, but the result is slightly in the opposite direction to that predicted. Hence Indonesian websites demonstrate results in the opposite direction predicted in Hypothesis 7.

\section{Summary of Hypothesised Results}

\begin{tabular}{cc}
\hline HYPOTHESIS & RESULT \\
\hline H1 Indo website Collectivism $>$ Anglo website & H1 NOT SUPPORTED l.p. \\
H2 Indo website Individualism $<$ Anglo website & H2 SUPPORTED \\
H3 Indo website Uncertainty Avoid $>$ Anglo website & H3 NOT SUPPORTED \\
H4 Indo website Power Distance $>$ Anglo website & H4 NOT SUPPORTED \\
H5 Indo website Masculinity $<$ Anglo website & H5 SUPPORTED \\
H6 Indo website Low Context $<$ Anglo website & H6 SUPPORTED \\
H7 Indo website High Context $>$ Anglo website & H7 NOT SUPPORTED \\
\hline
\end{tabular}




\section{Discussion}

The results show that the English and American companies have made a considerable effort in adapting their Indonesian websites to local culture. Three of the seven hypotheses proposed are well supported. Compared to their domestic websites the foreign companies' Indonesian websites displayed lower individualism, masculinity and context. These are cultural characteristics that should be minimized to remain culturally relevant in Asia.

Nevertheless, more adaptation is required. Four hypotheses relating to key cultural dimensions which define differences between Anglo-Western and Asian cultures remain unsupported. Compared to their domestic websites the foreign companies' Indonesian websites displayed lower Collectivism, Power Distance, Uncertainty Avoidance and High Context. These cultural characteristics should be raised rather than lowered to suit cultural sensitivities in Asia.

The results only reveal the difficulty of adapting the foreign companies' Indonesian websites to local culture. Hofstede (2001) notes that Asian and Western cultures can think and act very differently. They will have very different ideas on what makes a good website. Hence, to reach the target market, localization of web content is most important. Various studies indicate that web content and design must be sensitive to local culture (Bartikowski \& Singh, 2014; Cyr, 2008). The findings of this study suggest that more needs to be done to localize the Indonesian websites with regards to language and cultural characteristics.

Regarding language, the author reviewed 82 Indonesian websites of English and American companies operating in Indonesia. Only 40 of the companies had developed their websites in the local language. Most of the foreign companies that had websites in the Indonesian language focused on the local consumer as the end user. Companies that focused on businesses, on the other hand, were more likely to maintain their websites in English. Similarly, product-based businesses are more likely to translate their websites than service-based businesses.

The English and American companies' inclination towards using English in their Indonesian websites corresponds with earlier studies (Singh \& Boughton, 2005; Robbins \& Stylianou, 2003). Unlike Anglo companies, non-Anglo companies, however, had no qualms in using multiple languages and multiple websites to reach different markets. Local Indonesian sites, for example, tend to have a mix of Bahasa Indonesia and English. The English language is used because of its popularity and its status as a global language. To better compete, the Anglo companies may have to rethink their focus on the English language.

With regards to context, many websites are rather direct. They focused on telling it 'like it is.' Little effort is taken to be discreet and polite, a fundamental attribute of both collectivistic and high context cultures like Indonesia (Hall, 1976). For example, direct comparisons can sometimes be made with lesser quality locally made products. This can often be seen as arrogance and can offend local consumers. To avoid upsetting local sensitivities companies are advised to maintain a balance between self-promotion and humility to maintain good relations with the local community (Kim, 2002).

With references to collectivism, group and familial themes were mixed. Some of the company's websites were peppered with pictures of families and employee teams. Other websites were more likely to display pictures of individual achievement and recognition. Beyond pictures, however, few companies made an effort to build communities and generate a sense of belonging which is critical in collective, group-based countries like Indonesia (Gudykunst, 1996). The exception was companies like KFC and Mcdonalds that organized regular events to build links with the communities around them.

Further, a lot of the foreign company's Indonesian websites were word based with limited number of visuals, a key feature of individualistic, low context cultures. According to Hall and Hall (1990) individualistic, low context cultures like to have lots of data and facts before making decisions. In contrast, collectivistic, high context cultures prefer colors and pictures (Singh et al., 2005). Additionally, the Indonesian consumer may be less interested in information than with trust. Dinev and Hart (2005) note that high uncertainty avoidance cultures like Indonesia, value trust and security more than low uncertainty avoidance cultures.

Here is where community chats and discussion groups can play a bigger role. Although useful for interacting and building trust with online users, only a few of the websites utilize chat rooms and discussion boards. The exceptions were information technology companies such as Microsoft, Apple, and HP. The IT companies used the discussion forums rather successfully to address customer queries and provide support for their products and build trust.

Referring to Power Distance, pictures of international executives from headquarters are readily available on the company's Indonesian websites. The photos are available from embedded links to the foreign companies' domestic website. However, photos of local management personnel are much harder to find which may 
disappoint the local consumer. In hierarchical Indonesia, status, positions and responsibilities are essential (Hofstede, 2001). The local populace will like to see who is charge of the Indonesian unit of the company, and to whom they can they look to address their queries and complaints.

The foreign companies home websites are more comprehensive, compared to their Indonesian equivalent. High regulatory environment in the company's home country, demand that their domestic websites contain detailed financial and management information. There is no such legal requirement, however, for their Indonesian websites. Some of the Indonesian sites are rather scanty, missing executive profiles, important financial information, mission, vision and purpose, and focusing primarily on sales and promotion. Nevertheless, the missing information is vital as it can help the websites build credibility and trust. The missing information may also explain the fundamental differences in cultural characteristics between the foreign companies' domestic and Indonesian websites.

\section{Conclusion and Implications}

This study is on cultural adaptation of websites in Indonesia, There is a dearth of studies of this type in this developing but economically vibrant country. This study attempts to address this deficit. The focus of this study is to find out if the Indonesian websites of major multinational companies depict local cultural values. This study notes that many of the foreign companies have localized, that is, they have taken the effort to incorporate local cultural values and norms, but they are not doing it enough or not doing it right.

This study confirms previous studies that companies have begun to understand the importance of localizing their websites (Singh et al., 2006; Bartikowski \& Singh, 2014). For the most part, it is not appropriate or effective to provide a standardized online presence, as it is not sensitive to local cultural norms and values. Moreover, incorporating local cultural values will only afford the companies' concern a valuable competitive advantage over their competitors. Nonetheless, more work needs to be done in this regard.

This study provides insights on how companies can better adapt their Indonesian websites to local culture. Gommans et al. (2001, p. 51) note that websites should always be adapted to local conditions, but any 'adaptation should be based on a complete understanding' of local culture. Singh et al. (2003) framework for incorporating cultural elements has proven useful in this regard. According to Singh et al. (2003) framework, cultural elements relating to high, context, collectivism and high power distance need to be reviewed and emphasised in the foreign company's Indonesian websites to appropriately match local cultural sensitivities.

Additionally, the framework needs to be changed a little to incorporate social media. More companies are using both websites and social media to reach out to the local consumer. The majority of the companies investigated have linked their Facebook, Instagram and Linkedin Accounts to their websites. Facebook, in particular, has become a viral medium of communication for companies. It provides a means for customers to interact with the company. At the same time, companies can update customers with pertinent information and activities in real time (Kavoura, 2014; Mangold \& Faulds, 2009; Shin et al., 2015).

Hofstede (2001) notes that cultures do change, albeit slowly, hence the application of national cultural dimension to aspects of the website and other forms of communications remains highly relevant. Likewise, Chun et al. (2015), note that the rapid pace of modernization enveloping many emerging countries today do not change their core culture, they merely add another layer of cultural complexity. Thus, to be effective, communications approaches adopted by companies via websites or other means must be cognizant of the popular technologies and prevailing cultural norms.

\section{Limitations}

This study provides insights on how the foreign companies adapted their Indonesian websites. This study also provides insights on how the companies can better adapt their Indonesian websites to suit local cultural sensitivities. There are, however, several limitations associated with this study.

This study only focused on cultural values and norms under Hofstede (1980) and Hall (1990) cultural variability model. That is Singh et al. (2003) framework only takes into account cultural values and beliefs that may influence website design. Future studies can include language, colors, layout, structure, navigational links, multimedia and visual representation (Cyr \& Trevor Smith, 2004). Additionally, this study only focuses on one country, Indonesia. A multi-country study on how international companies adapt their websites to local culture may be appropriate.

There is also a need to study other cultures with different values and also economic and technological progress. Cyr (2013) notes that website preferences do not only vary based on culture but also on economic and technological advancement. Similar cultures with different economic and technological progress would 
invariably exhibit very different preferences.

Additionally, this study focuses on foreign companies' Indonesian websites only. A study on the local companies' websites such as Pertamina, WarungKretek would also be relevant in discovering the unique features of the truly local website and how they may differ from the foreign companies' culturally-adapted Indonesian websites.

\section{References}

Baack, D. W., \& Singh, N. (2007). Culture and web communications. Journal of Business Research, 60(3), 181-188. https://doi.org/10.1016/j.jbusres.2006.11.002

Badre, A. (2000). Effects of cross-cultural interface design orientation on world wide web user performance. Georgia Institute of Technology.

Barber, W., \& Badre, A. (1998). June. Culturability: The merging of culture and usability. In Proceedings of the 4th Conference on Human Factors and the Web, 7(4), 1-10.

Bartikowski, B., \& Singh, N. (2014). Should all firms adapt websites to international audiences? Journal of Business Research, 67(3), 246-252. https://doi.org/10.1016/j.jbusres.2013.05.010

Calabrese, A., Capece, G., Di Pillo, F., \& Martino, F. (2014). Cultural adaptation of web design services as critical success factor for business excellence: A cross-cultural study of Portuguese, Brazilian, Angolan and

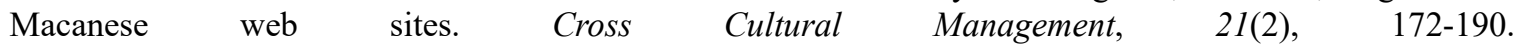
https://doi.org/10.1108/CCM-09-2012-0070

Carifio, J., \& Perla, R. (2008). Resolving the 50-year debate around using and misusing Likert scales. Medical Education, 42, 1150-1152. https://doi.org/10.1111/j.1365-2923.2008.03172.x

Chiou, W. C., Lin, C. C., \& Perng, C. (2010). A strategic framework for website evaluation based on a review of the literature from 1995-2006. Information \& management, 47(5-6), 282-290. https://doi.org/10.1016/ j.im.2010.06.002

Chu, S. C., Kamal, S., \& Kim, Y. (2013). Understanding consumers' responses toward social media advertising and purchase intention toward luxury products. Journal of Global Fashion Marketing, 4(3), 158-174. https://doi.org/10.1080/20932685.2013.790709

Chun, W., Singh, N., Sobh, R., \& Benmamoun, M. (2015). A comparative analysis of Arab and US cultural values on the web. Journal of Global Marketing, 28(2), 99-112. https://doi.org/10.1080/08911762.2014. 991015

Cyr, D. (2008). Modeling web site design across cultures: Relationships to trust, satisfaction, and e-loyalty. Journal of Management Information Systems, 24(4), 47-72. https://doi.org/10.2753/MIS0742-1222240402

Cyr, D. (2013). Website design, trust and culture: An eight country investigation. Electronic Commerce Research and Applications, 12(6), 373-385. https://doi.org/10.1016/j.elerap.2013.03.007

Cyr, D., \& Trevor Smith, H. (2004). Localization of Web design: An empirical comparison of German, Japanese, and United States Web site characteristics. Journal of the American society for information science and technology, 55(13), 1199-1208. https://doi.org/10.1002/asi.20075

Cyr, D., Head, M., \& Larios, H. (2010). Colour appeal in website design within and across cultures: A multi-method evaluation. International journal of human-computer studies, 68(1-2), 1-21. https://doi.org/10.1016/j.ijhcs.2009.08.005

Dinev, T., \& Hart, P. (2005).Internet privacy concerns and social awareness as determinants of intention to transact. International Journal of Electronic Commerce, 10(2), 7-29. https://doi.org/10.2753/JEC1086-4415 100201

Forbes. (2018). The World's Biggest Public Companies 2018. Retrieved April, 2018, from https://www.forbes.com/global2000/list/

Garson Statistics 2005 likert - Google Search. (n. d.). Retrieved November 4, 2018, from https://www.google.com.vn/search?rlz=1C1CHBF_enVN737VN737\&ei=2uHeW-XyBpTQ8wWRvJeQCg $\& \mathrm{q}=$ garson+statistics $+2005+$ likert\&oq $=$ garson+statistics $+2005+$ likert\&gs_l=psy-ab.3.33i160k1.76044.781 95.0.78907.7.7.0.0.0.0.228.906.0j6j1.7.0...0...1c.1.64.psy-ab..0.5.564...33i21k1.0.ME8-E1OuKbc

Garson, G. D. (2012). Hierarchical Linear Modeling: Guide and Applications. SAGE Publications.

George, D. (2016). IBM SPSS statistics 23 step by step: A simple guide and reference (14th ed.). Routledge, New York, NY. 
Gommans, M., Krishman, K. S., \& Scheffold, K. B. (2001). From brand loyalty to e-loyalty: A conceptual framework. Journal of Economic \& Social Research, 3(1).

Gromová, E., Müglová, D., \& Perez, E. (2017). Culture in advertising and advertising in culture: Communication, translation, representation. ArsAeterna, 9(2), 81-92. https://doi.org/10.1515/aa-2017-0011

Gudykunst, W.B., Matsumoto, Y., Ting-Toomey, S., Nishida, T., Kim, K., \& Heyman, S. (1996). The influence of cultural individualism-collectivism, self construals, and individual values on communication styles across cultures. Human communication research, 22(4), 510-543. https://doi.org/10.1111/j.1468-2958.1996. tb00377.x

Hall, E. T. (1990). Understanding cultural differences. Intercultural Press, Yarmouth, Me.

Hall, E. T., \& Hall, M. R. (1990).Understanding cultural differences. Nicholas Brealey Publishing, London.

Hall, E.T. (1976). Beyond Culture. Anchor Press, Doubleday.

Hamid, M. A. (2017). Analysis of visual presentation of cultural dimensions: Culture demonstrated by pictures on homepages of universities in Pakistan. Journal of Marketing Communications, 23(6), 592-613. https://doi.org/10.1080/13527266.2016.1147486

Hofstede, G. H. (1980). Culture's consequences: International differences in work-related values. Sage Publications, Beverly Hills, California.

Hofstede, G. H. (2001). Culture's consequences: Comparing values, behaviors, institutions, and organizations across nations (2nd ed.). Sage Publications, Thousand Oaks, Calif.

Hsieh, H. C. L. (2014). Evaluating the Effects of Cultural Preferences on Website Use, in: Cross-Cultural Design, Lecture Notes in Computer Science. Presented at the International Conference on Cross-Cultural Design, Springer, Cham, 162-173. https://doi.org/10.1007/978-3-319-07308-8_16

Hsieh, H. C. L., \& Dai Hong, S. (2013). Localization of Web Design: An Investigation of Culturally Preferred Web Attributes in Taiwan and the UK. In International Conference on Cross-Cultural Design (pp. 404-413). Springer, Berlin, Heidelberg.

Kavoura, A. (2014). Social media, online imagined communities and communication research. Library Review, 63(6/7), 490-504. https://doi.org/10.1108/LR-06-2014-0076

Kim, M. S. (2002). Non-Western perspectives on human communication: Implications for theory and practice. SAGE, Thousand Oaks, CA.

Kluckhohn, F. R., \& Strodtbeck, F. L. (1961). Variations in value orientations. Greenwood Press.

Luna, D., Peracchio, L. A., \& de Juan, M. D. (2002). Cross-cultural and cognitive aspects of web site navigation. Journal of the academy of marketing science, 30(4), 397-410. https://doi.org/10.1177/009207002236913

Mangold, W. G., \& Faulds, D. J. (2009). Social media: The new hybrid element of the promotion mix. Business horizons, 52(4), 357-365. https://doi.org/10.1016/j.bushor.2009.03.002

Pell, G., (2005). Use and misuse of Likert scales. Medical Education 39, 970-970. https://doi.org/10.1111/j.1365-2929.2005.02237.x

Pengnate, S. F., \& Sarathy, R. (2017). An experimental investigation of the influence of website emotional design features on trust in unfamiliar online vendors. Computers in Human Behavior, 67, 49-60. https://doi.org/10.1016/j.chb.2016.10.018

Reinecke, K., \& Bernstein, A. (2011). Improving performance, perceived usability, and aesthetics with culturally adaptive user interfaces. ACM Transactions on Computer-Human Interaction (TOCHI), 18(2), 8. https://doi.org/10.1145/1970378.1970382

Robbins, S. S., \& Stylianou, A. C. (2003). Global corporate web sites: An empirical investigation of content and design. Information \& Management, 40(3), 205-212. https://doi.org/10.1016/S0378-7206(02)00002-2

Shin, W., Pang, A., \& Kim, H. J. (2015). Building relationships through integrated online media: Global organizations' use of brand web sites, Facebook, and Twitter. Journal of Business and Technical Communication, 29(2), 184-220. https://doi.org/10.1177/1050651914560569

Singh, N. (2003). Analyzing the Web as a cultural document: An exploratory study of cultural values as depicted on country -specific websites. ProQuest Dissertations Publishing.

Singh, N., \& Boughton, P. D. (2005). Measuring website globalization: A cross-sectional country and industry 
level analysis. Journal of Website Promotion, 1(3), 3-20. https://doi.org/10.1300/J238v01n03_02

Singh, N., \& Matsuo, H. (2004).Measuring cultural adaptation on the Web: A content analytic study of US and Japanese Web sites. Journal of Business Research, 57(8), 864-872. https://doi.org/10.1016/S0148-2963(02) 00482-4

Singh, N., Furrer, O., \& Ostinelli, M. (2004). To localize or to standardize on the web: empirical evidence from Italy, India, Netherlands, Spain, and Switzerland. Multinational Business Review, 12(1), 69-88. https://doi.org/10.1108/1525383X200400004

Singh, N., Park, J. E., Chun, W., Moura, F. T., \& Kim, S. H. (2017). Strategic Insights into Localizing Web Communications: Evidence from South Korea. ACM SIGMIS Database: The DATABASE for Advances in Information Systems, 48(3), 69-82. https://doi.org/10.1145/3130515.3130520

Singh, N., Zhao, H., \& Hu, X. (2003). Cultural adaptation on the web: A study of American companies' domestic and Chinese websites. Journal of Global Information Management (JGIM), 11(3), 63-80. https://doi.org/10.4018/978-1-59140-468-2.ch012

Singh, N., Zhao, H., \& Hu, X. (2005). Analyzing the cultural content of web sites: A cross-national comparison of China, India, Japan, and US. International Marketing Review, 22(2), 129-146. https://doi.org/10.1108/02651330510593241

Statista. (2018). Indonesia: Internet penetration rate. Retrieved April, 2018, from https://www.statista.com/statistics/254460/internet-penetration-rate-in-indonesia/

Thorpe, K., Galassi, M., \& Franks, R. (2016). Discovering Indigenous Australian culture: Building trusted engagement in online environments. Journal of Web Librarianship, 10(4), 343-363. https://doi.org/10.1080/19322909.2016.1197809

Triandis, H. C., Bontempo, R., Villareal, M. J., Asai, M., \& Lucca, N. (1988). Individualism and collectivism: Cross-cultural perspectives on self-ingroup relationships. Journal of personality and Social Psychology, 54(2), 323. http://dx.doi.org/10.1037/0022-3514.54.2.323

Triandis, H. C., Chan, D. K. S., Bhawuk, D. P., Iwao, S., \& Sinha, J. B. (1995). Multimethod probes of allocentrism and idiocentrism. International journal of psychology, 30(4), 461-480. https://doi.org/10.1080/0020759950824658

Trompenaars, A. (2012). Riding the waves of culture: Understanding diversity in global business (Rev and updated 3rd ed.). McGraw-Hill, New York.

Trompenaars, F. (1996). Resolving international conflict: Culture and business strategy. Business strategy review, 7(3), 51-68. https://doi.org/10.1111/j.1467-8616.1996.tb00132.x

Tsikriktsis, N. (2002). Does culture influence web site quality expectations? An empirical study. Journal of service research, 5(2), 101-112. https://doi.org/10.1177/109467002237490

World Bank Group. (n. d.). Indonesia [Data]. Retrieved September, 2018, from World Development Indicators.(WDI) database.

\section{Copyrights}

Copyright for this article is retained by the author(s), with first publication rights granted to the journal.

This is an open-access article distributed under the terms and conditions of the Creative Commons Attribution license (http://creativecommons.org/licenses/by/4.0/). 